\title{
Nanoparticles from Cu-Zn-Al Shape Memory Alloys Physically Synthesized by Ion Milling Deposition
}

\author{
Luis Alberto López Pavón ${ }^{\mathrm{a}, \mathrm{b}}$, Enrique Lopez Cuellar ${ }^{\mathrm{a}, \mathrm{b}}$, Carmen Ballesteros ${ }^{\mathrm{c}}$, \\ Alejandro Torres Castro ${ }^{\mathrm{a}, \mathrm{b}}$, Azael Martínez de la Cruz ${ }^{\mathrm{a}, \mathrm{b}}$, Carlos José de Araújo ${ }^{\mathrm{d} *}$ \\ aniversidad Autónoma de Nuevo León - UANL, Av. Universidad, s/n, Cd. Universitaria, \\ CP 66450, San Nicolás de los Garza, Nuevo León, México \\ ${ }^{\mathrm{b}}$ Centro de Innovación, Investigación y Desarrollo en Ingeniería y Tecnología - CIIDIT, \\ Universidad Autónoma de Nuevo León - UANL, Km 10, Nueva Autopista al Aeropuerto Internacional de \\ Monterrey, CP 66600, Apodaca, Nuevo León, México \\ ${ }^{\mathrm{c}}$ Departamento de Física, Universidad Carlos III de Madrid, \\ Av. Universidad, 30, 28911, Leganés, Madrid, Spain \\ ${ }^{\mathrm{d}}$ Departamento de Engenharia Mecânica, Universidade Federal de Campina Grande - UFCG, \\ Av. Aprígio Veloso, 882, Bairro Universitário, CEP 58429-140, Campina Grande, PB, Brazil
}

Revised: November 25, 2011; Revised: February 3, 2012

In this research, an ion milling equipment was used to elaborate nanoparticles from $\mathrm{Cu}-\mathrm{Zn}-\mathrm{Al}$ alloys with shape memory effect. Two different compositions were used, target A: 75.22 Cu-17.12Zn-7.66Al at \% with an $\mathrm{Ms}$ of $-9{ }^{\circ} \mathrm{C}$ and target $\mathrm{B}: 76.18 \mathrm{Cu}-15.84 \mathrm{Zn}-7.98 \mathrm{Al}$ with an Ms of $20^{\circ} \mathrm{C}$. Nanoparticles were characterized by High Resolution Transmission Electron Microscopy, Electron Diffraction and Energy Dispersive X-ray Spectroscopy. The obtained nanoparticles showed a small dispersion, with a size range of 3.2-3.5 nm. Their crystal structure is in good agreement with the bulk martensitic structure of the targets. In this sense, results on morphology, composition and crystal structure have indicated that it is possible to produce nanoparticles of $\mathrm{CuZnAl}$ shape memory alloys with martensitic structure in a single process using Ion Milling.

Keywords: anoparticles, ion milling, shape memory alloy, CuZnAl

\section{Introduction}

Nanoparticles have different properties in comparison with bulk or even microparticles. This makes nanoparticles desirables for some applications, e.g. when a liquid is doped with metal particles in order to improve conductivity or heat transfer process. If those particles are in micrometer size or higher range they could get stuck into the pipe. Instead, nanoparticles flow better and they have $20 \%$ of their atoms near of the surface, allowing them to absorb and transfer heat more efficiently ${ }^{1}$.

$\mathrm{CuZnAl}$ alloys exhibit, in a certain range of composition, the Shape Memory Effect (SME), i.e. when a material have the capacity to recover their shape with a simple heating after suffer an apparent plastic deformation. SME is due to martensitic-austenitic phase transformation depending on the temperature. The lattice structure changes in $\mathrm{CuZnAl}$ alloys associated with the martensitic transformation are from the crystal structure $\mathrm{DO}_{3}$ or $\mathrm{L}_{2}$ at higher temperature (austenitic phase) to $18 \mathrm{R}$ (martensitic phase) at lower temperature. Along with this phase transformation occurs significant changes in mechanical, physical, chemical, electrical and optical properties, including yield stress,

*e-mail: carlos@dem.ufcg.edu.br elastic modulus, damping, hardness, electrical resistivity, thermal conductivity, thermal expansion and surface roughness ${ }^{2-8}$. These changes in properties could be exploited in nanoparticles if the martensitic-austenitic transformation occurs.

The influence of the grain size in the properties of Shape Memory Alloys (SMA) has been observed in different systems, especially the dependence of the martensitic transformation behaviour in nanostructured SMA. It has been reported that the transformation takes place in bulk materials after a severe deformation and different heat treatments when the grain size of the alloy is around $40 \mathrm{~nm}^{9-13}$. The development of SMA with controlled grain size is interesting for applications. It must be pointed out that, in bulk materials with nanograins, SME could be limited by grain size ${ }^{14-15}$. It was suggested that grain boundaries hinder the transformation. However grain boundaries should not be a limitation in nanoparticles, so it can be expected that the transformation will take place.

There are different methods for elaborating nanoparticles. They could be chemicals or physicals. Using physical methods, a good option to elaborate metallic and bimetallic nanoparticles, good results in stoichiometry can 
be obtained ${ }^{16}$. In the present study, metallic nanoparticles are elaborated from CuZnAl SMA bulks using a physical method, ion milling, trying to reproduce the chemical composition and the structure of the bulk. Ion milling is a physic process that involves physical vaporization of atoms from a surface by bombarding with a focused beam of energetic ions. In this work, a commercial ion milling equipment was used to elaborate nanoparticles from CuZnAl SMA. These nanoparticles were collected on a substrate or in a copper grid with lacey carbon for their later characterization by transmission electron microscopy (TEM). This process has previously proved its efficacy in the field of metallic and bimetallic nanoparticles deposition $(\mathrm{Ti}, \mathrm{Ni} \text { and } \mathrm{TiNi})^{16-18}$. The results obtained in this work also have shown that by this method, the structure of ternary $\mathrm{CuZnAl}$ alloys can be reproducible.

\section{Experimentation}

In this work, two different samples of $\mathrm{Cu}-\mathrm{Zn}$-Al SMA with different compositions were used as target. The samples were fabricated at the University of Bariloche, Argentina. The composition and the martensitic transformation temperature of the alloys were: of $75.22 \mathrm{Cu}-17.12 \mathrm{Zn}-7.66 \mathrm{Al}$ at $\%$ with an Ms of $-9^{\circ} \mathrm{C}$ for the sample $\mathrm{A}$ and of $76.18 \mathrm{Cu}-15.84 \mathrm{Zn}-7.98 \mathrm{Al}$ with an $\mathrm{Ms}$ of $20^{\circ} \mathrm{C}$ for the sample B.

Targets were first characterized using X-ray diffraction (XRD) and electron dispersive spectroscopy (EDX). The chemical composition of the targets was verified semiquantitatively with the EDX. XRD results at room temperature have indicated the coexistence of austenite and martensite phases in sample A, and only martensite phase was observed in sample $\mathrm{B}$, in agreement with the measured Ms temperatures of $-9{ }^{\circ} \mathrm{C}$ and $20^{\circ} \mathrm{C}$, respectively.
After their characterization, the targets were bombarded with $\mathrm{Ar}^{+}$ions accelerated at $5 \mathrm{keV}$ in an ion milling Gatan 691. The material removed from the target was collected on TEM copper lacy coal grids. The morphology and structure of the nanoparticles were characterized with a Philips Tecnai 20 FEG equipped with EDX and STEM (scanning transmission electron microscopy) modules, a Jeol 2010F TEM and a JSM-F7500 Jeol SEM in STEM mode.

\section{Results and Discussion}

\subsection{Characterization of nanoparticles from sample A with an $\mathrm{Ms}$ of $-9{ }^{\circ} \mathrm{C}$}

The micrograph of Figure 1a shows TEM images from sample A, where the size and distribution of the nanoparticles can be observed. The chemical analysis obtained "in situ" with the EDX detector of the TEM is not shown. The composition analysis was only qualitative due to the $\mathrm{Cu}$ of the grid and the specimen holder of the microscope. In order to avoid this effect in future works, grids of Ni or Mo should be utilized. Moreover, it can be confirmed that the three elements of the bulk material are presented. After TEM micrographs, the size distribution of the nanoparticles was measured. An example is shown in Figure $1 \mathrm{~b}$ where the number of nanoparticles was plotted against size. From those analyses the average size obtained is of $3.5 \pm 0.5 \mathrm{~nm}$.

In order to obtain information on the crystal structure of the nanoparticles and to identify the existing phases, diffraction pattern simulation (FTP) using the Fourier Transform of the high resolution transmission electron microscopy (HRTEM) images was done. Some examples

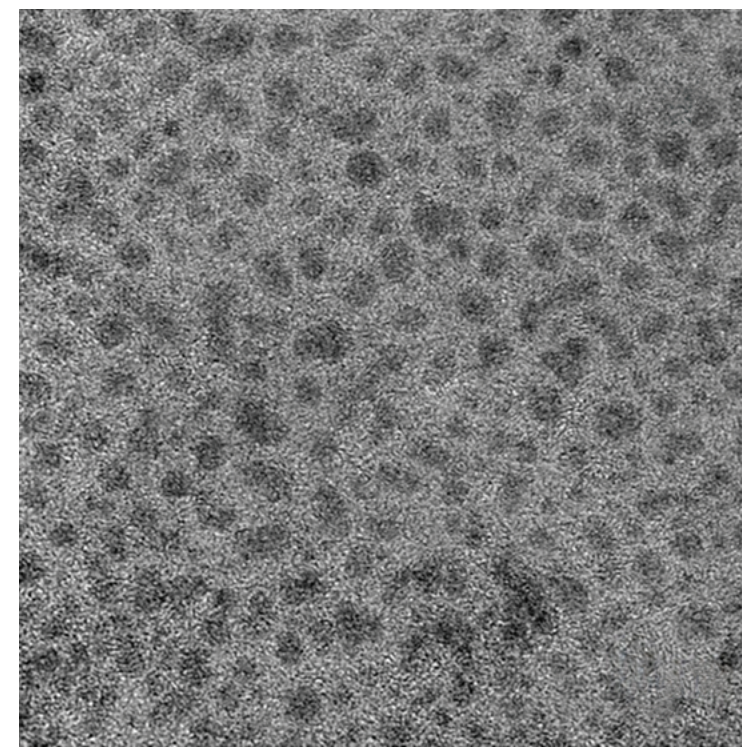

(a)

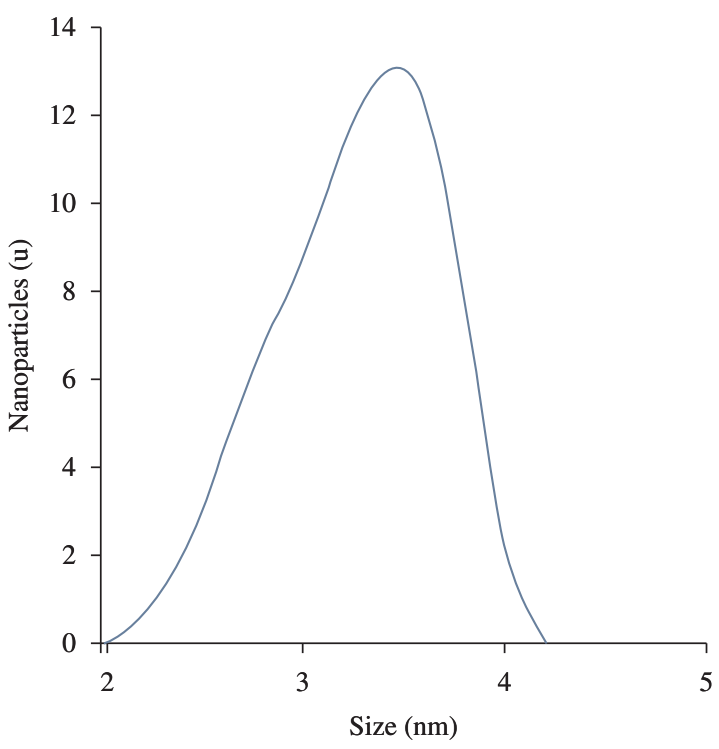

(b)

Figure 1. a) Nanoparticles distribution of sample A; b) Distribution of size. 

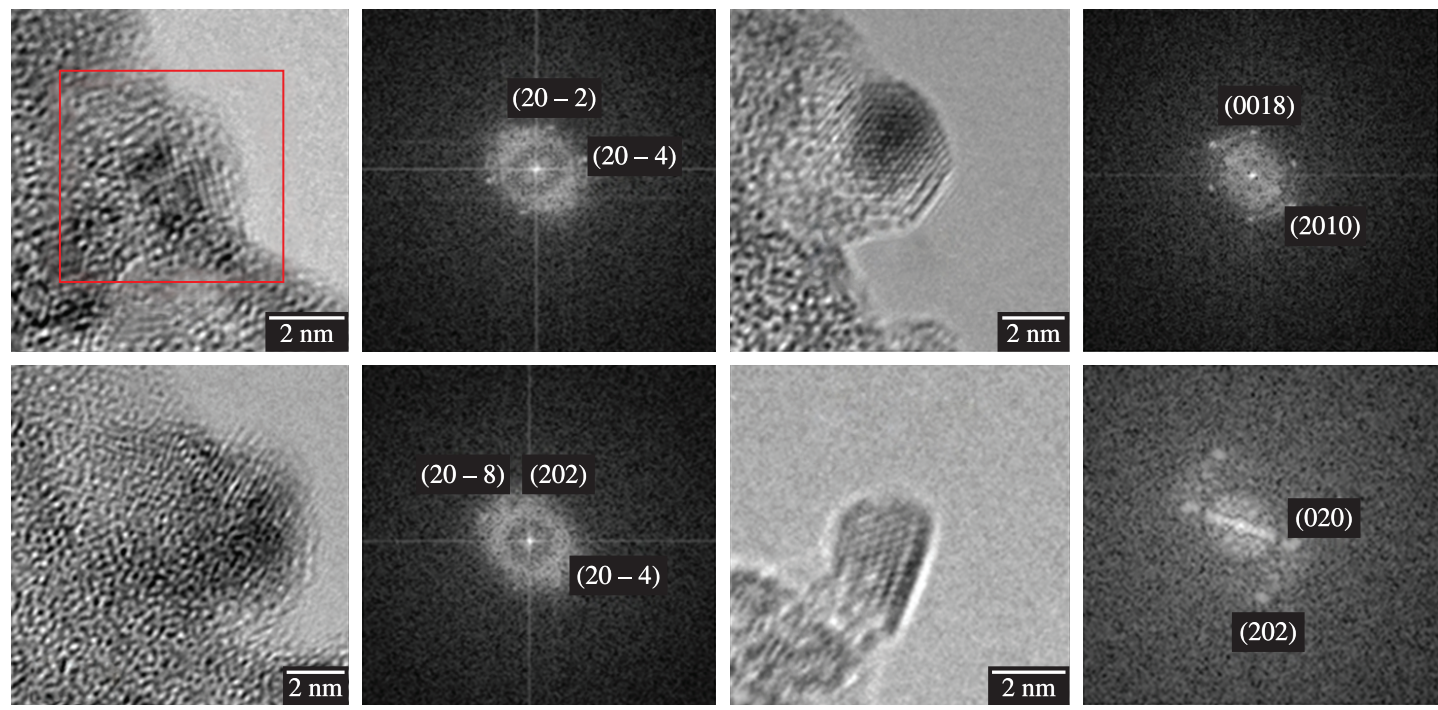

Figure 2. Nanoparticles of sample A and its Fourier transform with the martensite plane.

Table 1. Comparative of the interplanar distances between martensite phase in bulk (left), average measured at FTP of the nanoparticles (center) and martensite plane (right).

\begin{tabular}{|c|c|c|}
\hline Bulk (̊̊) & Nanoparticle $(\AA ̊) ~ \pm 0.06$ & Plane (martensite) \\
\hline 2.19 & 2.19 & $(20-2)$ \\
\hline 2.15 & 2.15 & $\left(\begin{array}{lll}2 & 0 & -4\end{array}\right)$ \\
\hline 2.12 & 2.11 & $\left(\begin{array}{lll}0 & 0 & 18\end{array}\right)$ \\
\hline 2.07 & 2. 05 & $\left(\begin{array}{lll}1 & 2 & 8\end{array}\right)$ \\
\hline 1.88 & 1.87 & $\left(\begin{array}{lll}2 & 0 & 10\end{array}\right)$ \\
\hline 1.47 & 1.44 & $(20-20)$ \\
\hline
\end{tabular}

are shown in Figure 2, where nanoparticles were selected and its FTP was obtained. The FTP is shown in the right side of each nanoparticle. Unfortunately the quality of the images and the corresponding FTP could not be improved because the nanoparticles are drifting after few seconds for all the observation conditions in the TEM. With the deficiencies revealed above, the distances measured in the FTP are in better agreement with that corresponding to the martensite phase. However, only the austenite phase is present in the bulk sample A. The last could be explained if there are small changes in chemical composition of the nanoparticles, shifting the phase transformation temperatures. On the other hand, during TEM observations the samples are cooled with liquid nitrogen and drift of the nanoparticles is always observed. Only after several seconds below of electron beam, both effects, small composition variations and low temperature TEM observation, can induce the formation/transformation of the martensite phase in the nanoparticles, even if the phase of the bulk material target was the austenite. The last behaviour is a potential explanation of the drift observed.

The comparison of the interplanar distances from four nanoparticles and distances of the bulk material in martensite phase are shown in Table 1 . Table 1 shows the interplanar distances of bulk material in the martensite phase (left), the interplanar distances of nanoparticles from the sample A (center) and finally the corresponding plane to the martensite phase. The distances presented in this table correspond to the nanoparticles of Figure 2. It must be noted that many other nanoparticles were analysed and in most of them the measured distances are in better agreement with the martensite phase. However, pure copper nanoparticles were also found, in good agreement with the change in chemical composition that was suggested.

It should be pointed out that with this sample was not possible to obtain a good electron diffraction image due to the constant drift of the nanoparticles below the electron beam when the TEM was in image/diffraction conditions. Other nanoparticles have presented these fluctuations when they are exposed to the electron beam, as was reported by W. Krakow et al. ${ }^{20}$. This suggest that, if the nanoparticles are in the martensitic phase, the electron beam could induce the phase transformation to a more stable phase (austenite) by increasing the nanoparticles temperature during its observation, being the origin of the instabilities observed during TEM analysis of the nanoparticles. Unfortunately it was not possible to measure and control the temperature of the sample to prove "in situ" the phase transformation, because of the TEM holder used in this work.

\subsection{Characterization of nanoparticles from sample B with an $\mathrm{Ms}$ of $20^{\circ} \mathrm{C}$}

The analysis of sample B followed the same procedure than the one of sample A. In Figure $3 \mathrm{a}$ it can be seen a homogenous distribution of nanoparticles indicating the efficiency of this method to elaborate nanoparticles with homogeneous size. The chemical composition after EDX spectra obtained "in situ", not shown here, indicate that the three elements of the bulk target are presented. In the 


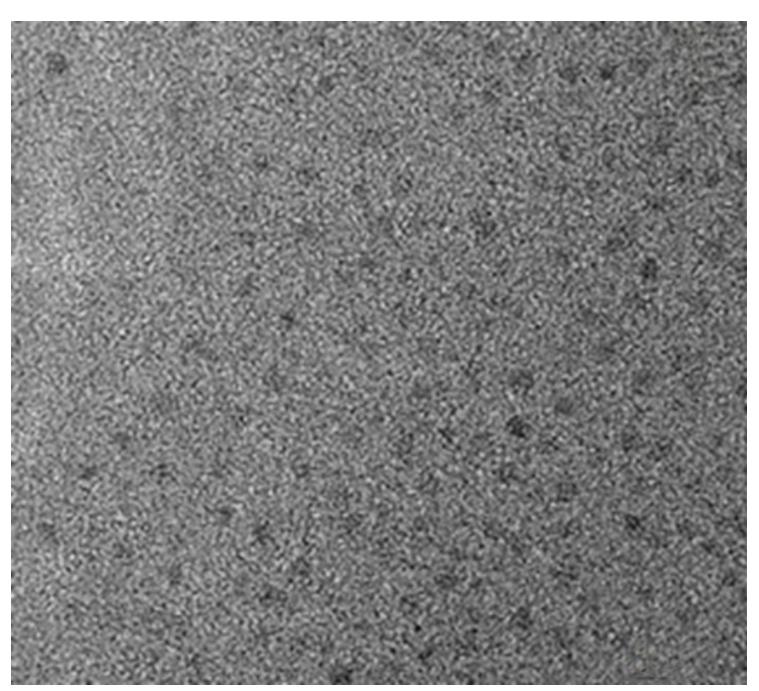

(a)

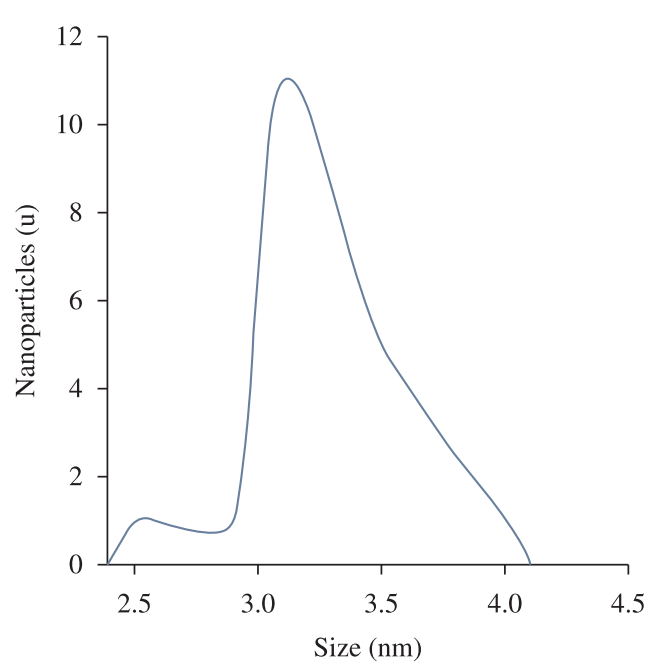

(b)

Figure 3. a) Nanoparticles distribution of sample B; b) Distribution of size.
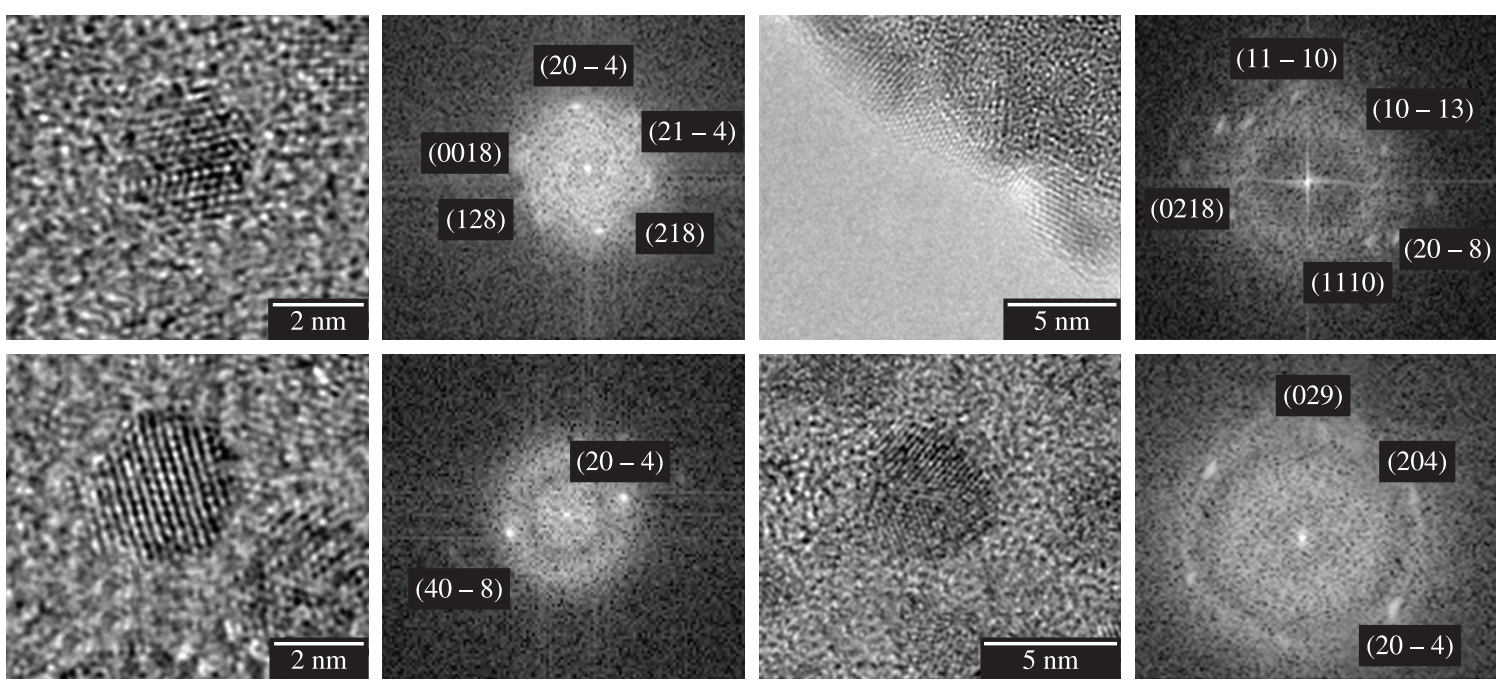

Figure 4. Nanoparticles of sample B and its Fourier transform with the martensite plane.

Table 2. Comparative of the interplanar distances between Bulk in martensite phase (left), nanoparticle analyzed (center) and the martensite plane corresponding (right).

\begin{tabular}{|c|c|c|}
\hline Bulk (̊̊) & Nanoparticle $(\AA ̊) \pm 0.06$ & Plane (martensite) \\
\hline 2.26 & 2.26 & (02 9) \\
\hline 2.19 & 2.18 & $\left(\begin{array}{lll}2 & 0 & 0\end{array}\right)$ \\
\hline 2.12 & 2.11 & $\left(\begin{array}{lll}0 & 0 & 18\end{array}\right)$ \\
\hline 2.15 & 2.15 & $\left(\begin{array}{lll}2 & 0 & -4\end{array}\right)$ \\
\hline 1.88 & 1.87 & $\left(\begin{array}{lll}2 & 0 & 10\end{array}\right)$ \\
\hline 1.0 & 0.99 & $(42-8)$ \\
\hline
\end{tabular}

Figure $3 b$, the size distribution of nanoparticles is presented; the average size of the nanoparticles is around $3.2 \mathrm{~nm}$.

As can be observed, according to the interplanar distances measured from the FTP in Figure 4, the nanoparticles from the sample B are in martensite phase, the same obtained in sample A. In Table 2, the average interplanar distances measured are in agreement with that corresponding to the bulk martensite phase.

Finally, in order to corroborate the last results, a selected area electron diffraction pattern was obtained from sample B. The interplanar distances were measured and indexed according to a martensite phase (Figure 5). These results reaffirm previous results obtained from FTP simulations in $2 \mathrm{D}$, so it could be confirmed that the nanoparticles keep the same phase of the bulk material used as targets, even thought, very probably with small differences in their composition and therefore in their transformation temperature (Ms). The results obtained in this study and the previously documented researches with $\mathrm{TiNi}$ alloys ${ }^{16-18}$ are in agreement that this method of synthesis is a very promising to obtain binary and ternary nanoparticles from metallic alloys. 


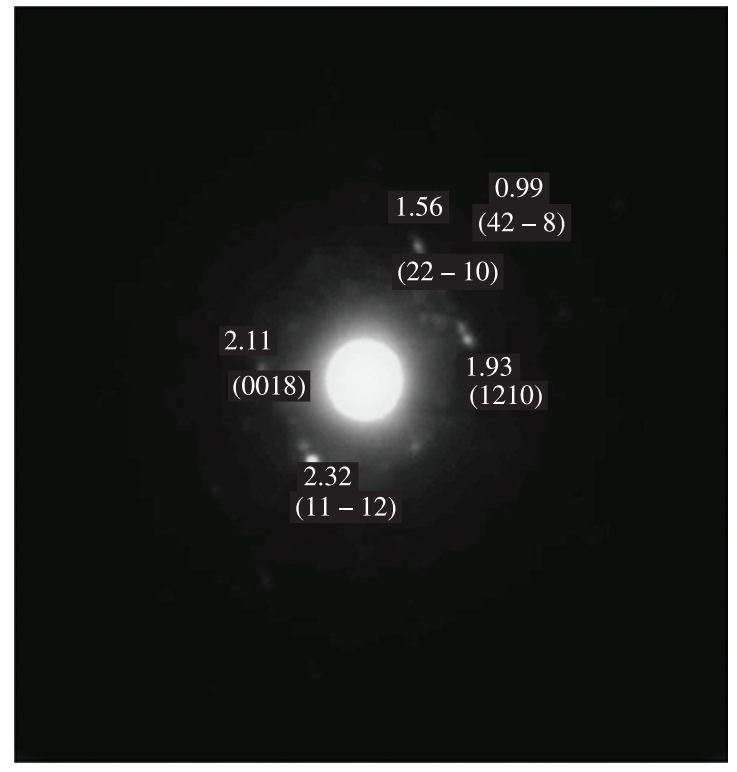

Figure 5. Electron diffraction pattern of nanoparticles from sample B, in brackets are indicated the martensite planes.

\section{Conclusions}

Two different compositions of CuZnAl alloys with shape memory effect have been used as target to elaborated nanoparticles by ion milling. Synthetized nanoparticles have a homogenous size of around 3.2-3.5 nm. The chemical compositions of nanoparticles obtained qualitatively by EDX have confirmed the presence of the three elements of the bulk material $(\mathrm{Cu}, \mathrm{Zn}$ and $\mathrm{Al})$. On the other hand, results of EDX have shown that it was not possible to have a complete control on the composition of all the nanoparticles. For this reason, in the same deposit it is possible to find differences in compositions between the elaborated nanoparticles. One important thing to notice is that the zinc remains in a very good proportionality in the synthetized nanoparticles, which is very hard by other methods due to its very low melting point. These results are really encouraging to keep researching in this area due to the possible applications of these nanoparticles.

Further work must be done with a special heating TEM holder to prove if the nanoparticles with martensitic or austenitic phase show the phase transformation and determine the transition temperature.

\section{Acknowledgements}

The authors would like to thank the University of Bariloche in Argentine for provide the bulk samples and I. Ortiz for assistance in experiments. This work was supported by the CIAM (Inter-American Collaboration in Advanced Materials) projects in Mexico (CONACYT, project 107462) and Brazil (CNPq, project 490912/2008-7).

\section{References}

1. Argonne National Laboratory and U.S Department of Energy. Why nanoparticles are better than microparticles. Argonne National Laboratory; 2004. Available from: <www.anl.gov/ Media_Center/News/2004/nanofluidsbig.html>.

2. Fu YQ, Du HJ, Huang WM, Zhang S and Hu M. TiNi-based thin film in MEMS application: a review. Sensors and Actuators A: Physical. 2004; 112:395-408. http://dx.doi.org/10.1016/j. sna.2004.02.019

3. Wu MJ, Huang WM and Chollet F. In situ characterization of TiNi based shape memory thin films by optical measurement. Smart Materials and Structures. 2006; 15:N29-N35

4. Cuniberti A, Niewczas M and Embury JD. Dislocaciones en monocristales $18 \mathrm{R} \mathrm{Cu}-\mathrm{Zn}$-Al deformados en el ragno anómalo de tensiones. In: Anais do 4th Coloquio Latinoamericano de Fractura y Fatiga; 2000; Neuquén. Neuquén; 2000. p. 491-497.

5. Norme Francaise. Alliage à mémoire de forme (AMF) Vocabulaire et mesures. 1991. 23 p. NF A 51-080.

6. Eskil M and Kayali N. X ray analysis of some shape memory $\mathrm{Cu}-\mathrm{Zn}$-Al alloys due to the cooling rate effect. Materials Letters. 2006; 60:630-634. http://dx.doi.org/10.1016/j. matlet.2005.09.019

7. De Mico G, Bohe AE and Pasquevich DM. Caracterización de aleaciones CuZnAl: estabilidad Térmica de las fases y descincación. In: Anais da Jornadas Sam, Congresso CONAMET, Simposio Materia; 2003; San Carlos de Bariloche. San Carlos de Bariloche; 2003.

8. Pelegrina JL and Ahlers M. Efectos de la difusión atómica en la martensita monoclínica de aleaciones CuZnAl. In: Anais da Jornadas Sam, Congresso CONAMET, Simposio Materia; 2003; San Carlos de Bariloche. San Carlos de Bariloche; 2003.

9. Fu YQ, Luo JK, Flewitt AJ, Huang WM, Zhang S, Du HJ et al. Thin film shape memory alloys and microactuators. International Journal of Nanomanufacturing. 2009; 2(3-4):208-226. http:// dx.doi.org/10.1504/IJCMSSE.2009.027483

10. Fu YQ, Du H, Huang W, Zhang S and Hu M. TiNi- based thin films in MEMS applications: a review. Sensors and Actuators A: Physical. 2004; 112:395-408. http://dx.doi.org/10.1016/j. sna.2004.02.01

11. Winzek B, Schmitz S, Rumpf H, Sterzl T, Hassdorf R, Thienhaus $\mathrm{S}$ et al. Recent developments in shape memory thin film technology. Materials Science and Engineering: A. 2004; 378:40-46. http://dx.doi.org/10.1016/j.msea.2003.09.105

12. Vishoni R and Kaur D. Size dependence of martensite transformation temperature in nanostructed $\mathrm{Ni}-\mathrm{Mn}-\mathrm{Sn}$ ferromagnetic shape memory alloy thin film. Surface and Coatings Technology. 2010; 204:3773-3782. http://dx.doi. org/10.1016/j.surfcoat.2010.04.053

13. Filonov MR, Brailovski V and Prokoshkin SD. A study of structure formation in $\mathrm{Ti}-\mathrm{Nb}-\mathrm{Zr}$ shape memory alloys for medical application. Journal of Physics. 2011.

14. Prokofiev EA, Burow JA, Payton EJ, Zarnetta R, FrenzelJ, Gunderov DV et al. Suppression of $\mathrm{Ni}_{4} \mathrm{Ti}_{3}$ Precipitation by Grain Size Refinement in Ni-Rich NiTi Shape Memory Alloys. Advance Engeneering Material. 2010; 12(8). 
15. Zehetbauer M, Grössinger R, Krenn H, Krystian M, PippanR, Rogl P et al. Bulk Nanostructured Functional materials By Severe Plastic Deformation. Advance Engineering Material. 2010; 12(8).

16. Sree Harsha KS. Principle Vapor Deposition of Thin Films. Elsevier; 2005.

17. Castro AT, Cuéllar EL, Méndez UO and Yacamán MJ. Cristal structure of TiNi nanoparticles obtained by Ar ion beam deposition. Materials Science and Engineering: A. 2008; 481-482:476-478. http://dx.doi.org/10.1016/j. msea.2007.01.192
18. Castro AT, Cuéllar EL, Méndez UO and Yacamán MJ. Advances in developing TiNi nanoparticles. Materials Science and Engineering: A. 2006; 438-440:411-413. http://dx.doi. org/10.1016/j.msea.2006.02.157

19. Castro AT, Cuéllar EL, Méndez UO. Ni nanoparticles elaborated with an $\mathrm{Ar}$ ion polishing technique. Materials Research Society symposium proceedings. 2004; 818.

20. Krakow W, Yacaman MJ and Aragón JL. Observation of quasimelting at atomic level in Au nanocluster. Physical review B. 1994; 49:10591-10596. http://dx.doi.org/10.1103/ PhysRevB.49.10591 